\title{
Embedding additive particles in the sentence information structure: How L2 learners find their way through positional and prosodic patterns
}

\author{
Cecilia Maria Andorno (Torino) and Giuseppina Turco (Stuttgart)
}

\begin{abstract}
Since 1986, Klein pinpointed the 'embedding problem' among the main tasks L2 learners have to cope with in L2 speaking, the term referring to the need of linking the semantic content of a sentence to the information already available in the ongoing discourse. Research in L2 acquisition has shown that, even when the lexical and morphosyntactic structures needed to express specific information configurations are in place, learners can still lack the ability to use them in the ongoing discourse according to target language preferences, thus sticking to their source language preferences (Carroll \& Lambert 2003; Dimroth \& Lambert 2008; Lambert, Carroll \& von Stutterheim 2008).

Use of additive particles can pose similar 'embedding' problems, as they typically occur in a peculiar, non-canonical information configuration, in which a given predicate - available in the ongoing discourse - is claimed to hold for a new referent, which is added to other - given, available - referents.

Dimroth et al. (2010), comparing native speakers productions on the basis of the same narrative task (the Finite Story retelling), show that speakers of Germanic (Dutch, German) and Romance (French, Italian) languages differ in the way they embed additive particles in the sentence information structure. Our study focuses on the use of additive particles by intermediate learners of two language pairs (Italian L1 > German L2 and viceversa) in the Finite Story retelling. Results show that, in embedding additive particles (IT anche, GE auch) in the sentence structure, intermediate learners tend to adopt patterns that are compatible with the L1 both at positional and at prosodic level, thus partly discarding more target languagespecific patterns.
\end{abstract}

\section{$1 \quad$ Introduction}

In describing the learning problems adult second language (L2) learners have to cope with when communicating in L2, Klein (1986) mentioned the "embedding problem". It has to do with the contextual information a speaker has to take into account for building his message on the basis of his interlocutor's state of knowledge and of his own communicative goals. Natural languages always express embedded (contextual) meaning. This can turn into a useful resource for initial learners, as they can exploit the information available in the context in 
order to compensate for their linguistic limitations. Later on, learners will be able to use linguistic means to communicate those parts of meaning that are not contextually available, thus becoming more contextually independent. However, the need for embedding sentences in the on-going discourse never falls away; and as long as the learner variety develops, new problems can arise for a felicitous embedding of his sentences in discourse.

Crucially, additive particles represent a test-bed for learnability problems. They can be a useful strategy to recur to, especially in initial varieties: Me too! could be a simple and yet perfectly fit sentence for a learner just after someone has said he wants a cake. However, when the learner is able to produce a more complex grammar (e. g., I want a cake), he still has to face the problem of linking his sentences to the on-going discourse. More clearly, if he wants to express the same wish for a cake (and not, say, for a cake and something else), he has to embed an additive particle into his fully verbal sentence: I also want a cake vs. I want a cake too.

A first problem with the embedding of additive particles is that their semantic contribution may change according to their position into the sentence structure and their prosodic realization. Compare, for instance, sentences 0 to $0:{ }^{1}$

Auch Jan trinkt ein Bier

'Jan too drinks a beer' (as someone else does)

(3) Jan trinkt auch ein Bier

'Jan too drinks a beer' (as someone else does)

'Jan drinks a beer too' (and he also drinks something else)

The semantic value of the additive particle is only fully determined by its scope (cf. Introduction to this special issue), and the scope of the additive particle is mainly expressed through positional and prosodic means (König 1991). To properly use additive particles in the sentence, learners have therefore to learn the specific positional-prosodic patterns available in the target language, that is the grammar of scope.

A second problem is that most languages do not make use of a single positional-prosodic configuration for the main constituents of a sentence, but are provided with various options, depending on the informative role of its constituents. Compare 0 and 0 :

[Context: Was hat Jan heute getrunken?

'What did Jan drink today?']

Jan hat heute ein Bier getrunken

Jan has today a beer drunk

'Today Jan drank a beer'

(5)

[Context: Wer hat heute ein Bier getrunken?

'Who drank a beer today?']

a. Ein Bier hat heute Jan getrunken

a beer has today Jan drunk

b. Jan hat heute ein Bier getrunken

Jan has today a beer drunk

'Jan drank a beer today'

While in (4) Bier acts as the information focus of the sentence, in (5) a. and b. the focus is Jan. When using an additive particle, the learning task is to map a scope-structure over an

1 In the examples, bold letters signal the presence of a focal accent. 
Embedding additive particles in the sentence information structure: How L2 learners find their way through positional and prosodic patterns

already syntactically and informationally organized sentence: besides embedding the additive particle in the sentence, a learner has to fit the sentence in the discourse. From a learner point of view, embedding additive particles in a sentence is therefore a complex task, involving the manipulation of different organization levels at a time. This is what we here refer to as the "embedding problem" for additive particles.

A further problem is that evidence available in the input over the grammar of scope and information structure in the target language often lacks of transparency: the same linguistic means, namely position and prosody, have rather different functions at the same time, expressing semantic and syntactic features, information structure, scope phenomena, illocutionary force. The input does not offer clear-cut evidence over the availability of specific patterns in the target language. Several patterns are found in the input, with rather subtle meaning differences that can be hard to discriminate; moreover, the choice among alternatives can sometimes be described more as a matter of preference or "nativelikeness" (namely, of frequency), rather than a matter of acceptability.

The goal of this paper is to investigate the positional and prosodic properties of additive elements in sentence structures produced by L2 learners. In particular, we will compare German and Italian native speakers with Italian learners of German and German learners of Italian, and show how learners deal with the complex tasks of embedding the additive particle (namely, anche in Italian, auch in German) in the sentence.

The paper is organized as follows: we first review previous studies on the acquisition and use of additive particles in L2 and define our research goals in more detail (cf. section 2). Section 3 describes our participants (the control groups of native speakers and the target groups of learners), the elicitation procedure, and the dataset. Results for both the native speakers and the learner groups are presented in section 4. Finally, we discuss our findings in relation to previous studies and the implications of the embedding problem for L2 acquisition.

\section{Background and research goals of the current study}

Previous researches show that the second language acquisition of additive particles unfolds over time and in different ways, from early to later stages. Untutored learners of different target and source languages have been shown to use additive particles since earlier on (Becker/Dietrich 1996; Dimroth 1998; Andorno 2000; Benazzo 2005). In initial stages, they tend to follow an "adjacency principle" for scope marking: additive particles are always close to - typically before - the constituent in its scope. With the first emergence of the finite verb, the post-finite position of the additive particle starts to appear (Becker/Dietrich 1996; Dimroth 1998) in languages such as German, French or English, for which such a position is available as the wide scope position (König 1991; cfr. also De Cesare, in this volume). Yet, the postfinite position is still not frequent in full-fledged learner varieties and it does not immediately come along with a proper prosodic realization (Becker/Dietrich 1996; Dimroth 1998; Benazzo 2005; see also Andorno 2005 for the post-finite position in Italian L2).

Cross-linguistic differences also arise, both due to the target and the source language pairs in contact. A sentence peripheral position is observed in learner varieties when it is frequent in the target language (initial position in Italian, Andorno 2000; final position in French, 
Benazzo 2005). A preference towards the most frequent patterns of the source language is sometimes observed. Italian learners of German are more inclined to the adjacency principle compared to other learners (Dimroth 1998; Benazzo 2005); compared to native speakers, they tend to overuse the adjacent over the post-finite position, even at a high level of proficiency (Benazzo/Andorno 2010). When speaking French, German-French bilingual speakers adopt the post-finite position much more often than French monolingual speakers, in line with German positional preferences (Leray 2009). On the other hand, positional patterns available in the source language, but rare or absent in the target language, are discarded, at least at advanced stages of acquisition, as is the case for the post-finite position in Italian spoken by German speakers (Benazzo/Andorno 2010).

To sum up, previous results show that, even if additive particles appear early in learner varieties, learners continue working on the rules for the embedding of such particles in the sentence structure across all the acquisitional stages; moreover, results show that learners are sensitive to the frequency of the patterns available in the native and target language pairs involved. However, previous work has mainly investigated positional issues, while the prosodic property of particles in L2 acquisition has been only occasionally (Becker/Dietrich 1996; Dimroth 1998; Andorno 2000; Benazzo 2005) and not yet systematically investigated. In particular, previous studies on the L2 prosodic encoding of information structure have shown that intonational patterns produced by learners may be strongly influenced by their native language. Transfer from the native language can apply at different levels of the linguistic structure, from the inventory of intonational patterns to the phonetic implementation of the same intonational pattern (see, for instance, Mennen 2004) and, even more relevant to our case, in the way these patterns are used to convey meaning. We also know that even advanced learners often fail to use appropriate intonational patterns when marking information structure categories like focus (e. g. Rasier/Hiligsmann 2007) or topic (e. g. Turco/Gubian 2012).

On the basis of previous work showing differences between Italian and German native speakers on the building of the sentence base structure and the embedding of additive particles (Dimroth/Andorno/Benazzo/Verhagen 2010), here we investigate the embedding of the additive particle anche in L2 Italian and auch in L2 German. In particular, we analyse film-retellings produced by intermediate learners - already able to master the morphosyntactic base structures of the target language - and compare them with film-retellings by Italian and German native speakers. With respect to natives, our aim is to investigate more closely the interaction between the positional and the prosodic patterns of additive particles in each language: an aspect that has not been previously addressed (cf. Dimroth et al., 2010). Concerning learners, we ask the following research questions:

a. Do intermediate learners adopt the target language patterns for embedding additive particles in the sentence?

b. Are there any mismatches between the positional and prosodical patterns of additive particles in the learner variety?

c. With respect to points $a$. and b. is any cross-linguistic influence to be seen? 
Embedding additive particles in the sentence information structure: How L2 learners find their way through positional and prosodic patterns

\section{The Experiment}

\subsection{Participants}

Nine German learners of Italian L2 (3 males, 6 females, age average $=23$ ) and 9 Italian learners of German L2 (4 males, 5 females, age average $=22$ ) were randomly chosen out of a film-retelling corpus elicited with the video-clip The Finite Story (see Dimroth et al. 2010 and Benazzo/Dimroth in this volume for details); they had lived in the target language country for up to 6 months at the time of the recordings. They were all university students and mostly tutored learners with a B1-B2 competence level (according to the Common European Framework of Reference, cfr. CEFR 2011). The data collection took place during a period of stay in the target language country (Italy for German learners, Germany for Italian learners) for an Erasmus or similar student exchange program.

The learner data have been compared with a control group of 20 Italian native speakers (already described in Dimroth et al. 2010) and 9 German native speakers (3 males, 6 females, age average $=24$ ). Data from native speakers are partly coming from previous studies on the same film-retelling corpus (Dimroth et al. 2010; Andorno/Interlandi 2010).

\subsection{Materials and procedure}

The structure of the video-clip was specifically designed to elicit sentences with additive particles (i. e., anche and auch) having different scope properties.

The video-clip story was retold one sequence at a time, for a total of 31 sequences of a few seconds each. Speakers were free to talk as long as they want. This elicitation technique allowed us to have the benefits of collecting spontaneous production data (i. e., learners were not influenced by any verbal stimulus in their choice of sentence organization), while preserving the comparability of the sentences to analyse.

All film-retellings have been digitally recorded and later transcribed in CHAT format.

\subsection{Data selection}

For the current study, we selected sentences containing additive particles (namely, It. anche and Ger. auch) and sharing a number of syntactic and informational properties. This selection enabled us to describe the variability of learner productions against a limited and well-defined corpus of comparable target language sentences.

As for the syntactic properties, we only considered sentences containing an additive particle with scope over the subject NP.

The informational properties of the selected sentences are described in Table 1, which illustrates the information flow of the plot and the content of the sequences immediately preceding the selected ones: 


\begin{tabular}{|l|l|}
\hline Opening sequence: & Mr. Blue, Green and Red in their apartments. \\
\hline Sequence 1: & Mr. Blue going to sleep \\
\hline Sequence $2 *:$ & Mr. Green going to sleep \\
\hline Sequence $3 *:$ & Mr. Red going to sleep \\
\hline$[\ldots]$ & *sequences selected for the analysis \\
\hline Sequence $\mathrm{n}:$ & Mr. Green jumping from window \\
\hline Sequence $\mathrm{n}+1$ *: & Mr. Red jumping from window \\
\hline
\end{tabular}

Table 1: Information flow of the stimulus The Finite Story

Given the information flow of the plot and the semantic content of the sequences, whenever an additive particle is used in the selected sentences, it must be interpreted as having scope on the underlined referent, no matter its position or prosodic shape. Therefore, in the selected sentences, the referent in the scope of the additive particle has the following properties: a) It is already known from the plot; b) It is one of the main characters of the story; c) It is the event controller or the higher semantic case. According to models of discourse organization (e. g. Levelt 1989; Lambrecht 1994), such a referent should be the best candidate for the topic role. However, when the flow of changed and maintained information across the sequences is considered, the identity of the referent in the scope of the particle represents the only changed information with respect to preceding sequences, while the predicate is maintained: this peculiar information flow, typical of sentences containing additive particles, can candidate the referent in the scope of the particle for the focus role.

To sum up, the context in which the selected sentences are embedded encourages - rather than forcing - a specific information structure for the sentence to be produced. Examples (8ad) below, referring to Sequence 2 in Table 1, show this point. Native speakers of Italian can construct the referent in the Sequence either as a topic subject, with a sentence with SV order (ex. 8a and c), or as a focus subject, as signalled by the postposition of the subject (examples ( $8 \mathrm{~b}$ and $\mathrm{d}$ ). Moreover, speakers can produce an additive particle, as in (6) c-d, but can also leave the additive relation as unmarked, as in (6) a-b:

(6) a. Il signor Verdi va a dormire

b. Adesso va a dormire il signor Verdi

c. Anche il signor Verdi va a dormire

d. Adesso va a dormire anche lui

In other words, while speakers can choose different ways of selecting and organising information (or, different "perspectives", according to von Stutterheim/Klein 2002; Levelt 1989), we know that all the sentences of our corpus share the above-mentioned syntactic, semantic and informative properties and are therefore highly comparable. Whenever we find differences in the positional and prosodical structure of the sentences produced by the native speakers and the learner groups, we can then discard semantic and informational interpretations and consider the learner specificities as part of the grammar of scope of the learner variety. 
Embedding additive particles in the sentence information structure: How L2 learners find their way through positional and prosodic patterns

\subsection{Data annotation}

Our corpus comprises a total of 224 sentences containing an additive element - anche for Italian and auch for German. All sentences were positionally analysed; the analysis took into account the position of the NP in the scope of the additive particles (i. e., the subject NP) with respect to the overall sentence and to the verb, and the position of the additive particle. The datasets for the prosodic analysis are subsets of the datasets for the positional analysis (116 utterances in total); we had to exclude several sentences because of overlapping noises or voices, hesitations or reformulations; we also excluded cases containing embedded sentences that interrupt the root sentence. The prosodic analysis took into account the prosodic contour of the sentence, with particular attention to the additive particle and the constituent in its scope. The prosodic features were analysed by using Praat (Boersma/Weenink 2012).

\begin{tabular}{|l|l|l|l|l|}
\hline $\begin{array}{l}\text { Sentences with } \\
\text { additive particles }\end{array}$ & Italian natives & German natives & $\begin{array}{l}\text { Italian learners } \\
\text { of German }\end{array}$ & $\begin{array}{l}\text { German learners of } \\
\text { Italian }\end{array}$ \\
\cline { 1 - 4 } & 96 & 40 & 44 & 44 \\
\cline { 1 - 3 } Prosodic analysis & 31 & 29 & 27 & 29 \\
\hline
\end{tabular}

Table 2: Number of sentences containing an additive particle (i. e., anche and auch) positionally and prosodically analysed for each language group.

In what follows we will present the positional and prosodic analyses of the native datasets (i. e., Italian, German) followed by the analyses of the two learner datasets (i. e., German learners of Italian, Italian learners of German).

\section{$4 \quad$ Results}

\subsection{Native speakers}

\subsubsection{Italian natives}

The analysis of the Italian native dataset reveals three position of anche in the sentence base:

1. in $\mathrm{S}(\mathrm{ubject}) \mathrm{V}(\mathrm{erb})$ structures anche is either produced in sentence-initial position, immediately preceding the NP (coded as 'anche NP VP');'2

2. $\quad$ or immediately following the NP ('NP anche VP');

3. in VS structures anche is produced in post-verbal position, immediately preceding the NP ('VP anche NP').

2 NP stands for noun phrase, VP for verb phrase. A colour code is used in Figures 1, 2, 4 and 5 to identify the same positional structures in all datasets. In all figures, numbers over the bars indicate the amount of cases for each pattern. 
Figure 1 shows the distribution of these three positional patterns in Italian native speakers.

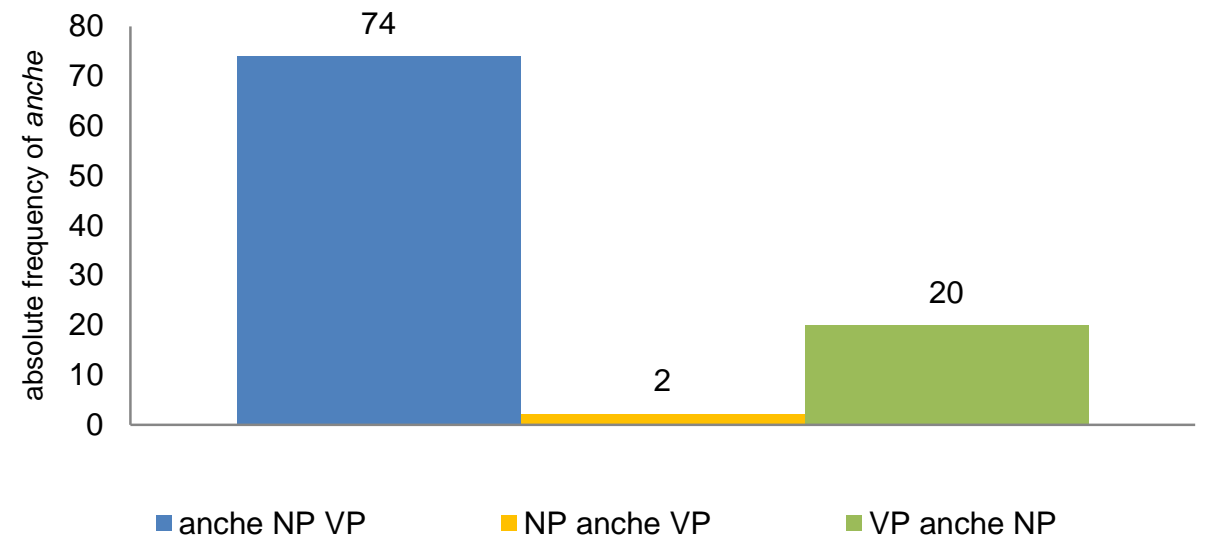

Figure 1: Positional embedding of the additive particle anche produced by 20 Italian native speakers, counts $(\mathbf{n}=96)$.

In all patterns the additive particle anche either immediately precedes (in most of the cases: 'anche NP VP' and 'VP anche NP') or follows (very rarely: 'NP anche VP') the subject NP in its scope. However, different structures are observed if we take into account the overall sentence organization both at a positional and prosodic level. From a positional point of view, the unmarked SV structure, with anche located before the NP ('anche NP VP' in ) is by far the most frequent pattern. Within these SV sentences, we find two prosodic contours. The most frequent one (i. e., 20 occurrences out of $26 \mathrm{SV}$ sentences of the prosodic dataset $^{3}$ ) conforms to the pattern commonly described in the literature for the Italian unmarked declarative sentences (see Firenzuoli/Signorini 2003; Mereu/Frascarelli 2006; Crocco/Savy 2007, among others) ${ }^{4}$. Such a pattern isolates the initial topic component (i. e., anche + the subject NP) with a rising-falling contour (the so-called hat pattern contour), while the following VP is realised with a gradual fall and carries the major pitch movement. This pattern is illustrated in Figure 2:

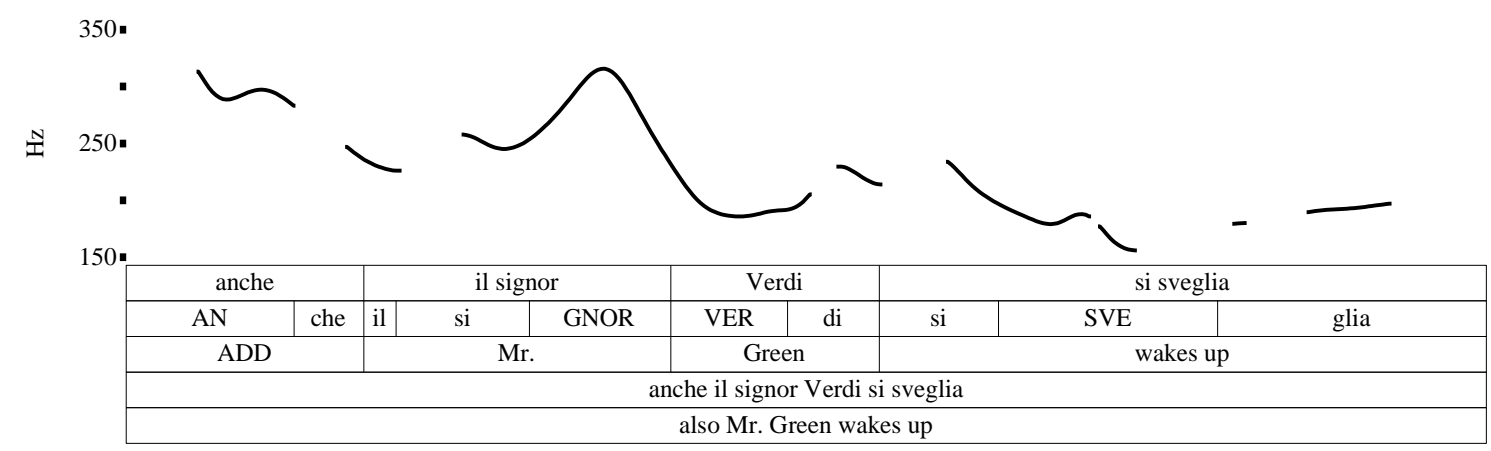

Figure 2: Pitch track example of 'anche NP VP' with a rising-falling contour on the NP, uttered by an Italian native speaker.

3 See Appendix A for more details on the number of sentences analysed prosodically.

4 For more details on the prosodic analysis of the Italian native speakers dataset see Andorno/Interlandi (2010). 
Embedding additive particles in the sentence information structure: How L2 learners find their way through positional and prosodic patterns

In the remaining SV cases (6 out of 26 sentences), sentences are realised with a different prosodic contour: the major focal movement (the falling of F0 on the last accented syllable) is observed on the initial constituent [anche + subject NP], while the following VP is deaccented, as illustrated in Figure 3.

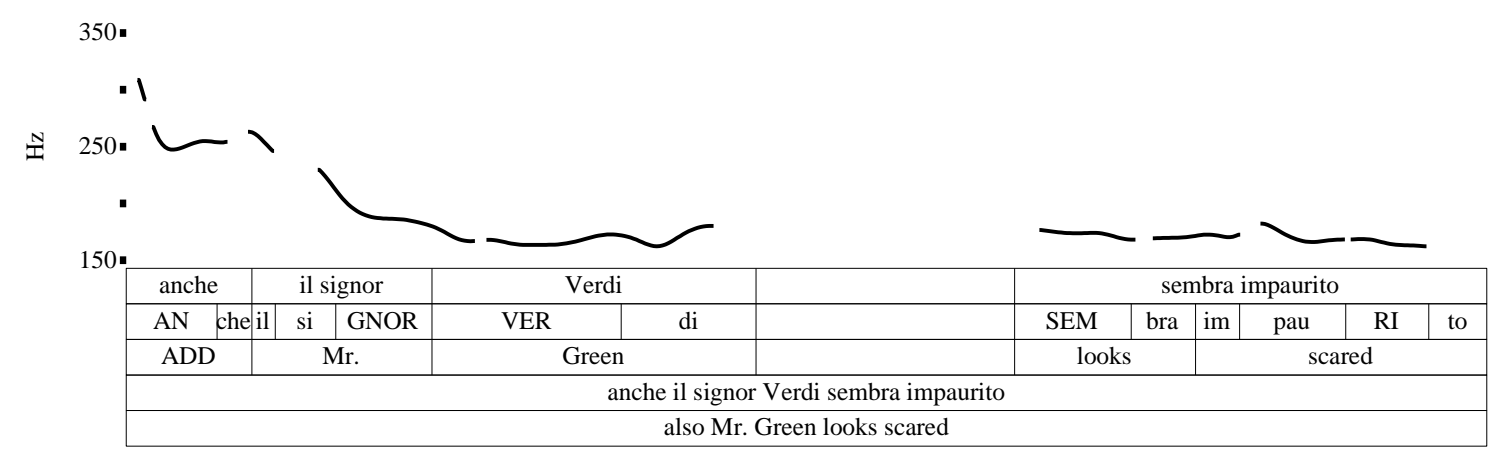

Figure 3: Pitch track example of 'anche NP VP' with a falling contour on the NP, uttered by an Italian native speaker.

These realizations show strong prosodic similarities with cases of focus-fronting reported in Cresti/Firenzuoli (2002) and in Bocci/Avesani (2006). Such a focus-fronting interpretation also holds for our cases, as the subject NP represents the only new information in the sentence. For these reasons, we are inclined to conclude that in these cases the initial [anche+ $\mathrm{NP}]$ has the focal role.

The remaining sentences ('VP anche NP' in) are realised with a VS order, with anche preceding the NP. This pattern is generally used in Italian to mark the subject as focus. The prosodic analysis confirms this interpretation: the sentences are realised as a single prosodic unit, the pitch follows a gradual fall until the minimum and aligns with the last nuclear syllable, in which the typical falling-rising contour of the focus is realised (see Andorno/Interlandi 2010: 82). This pattern is illustrated in Figure 4.

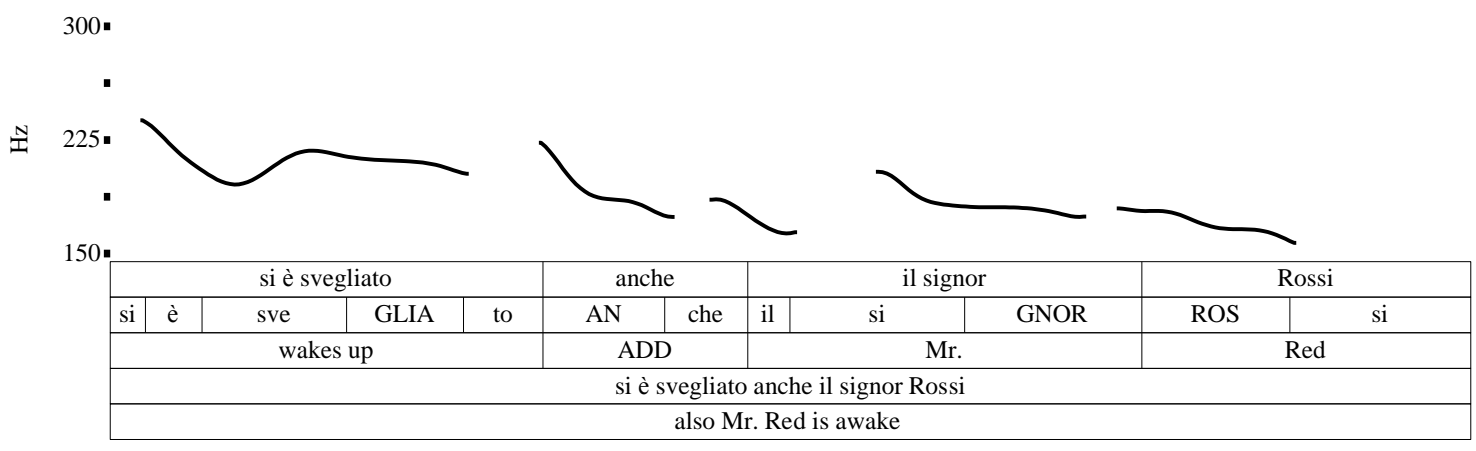

Figure 4: Pitch track example of 'NP anche VP' with a gradual fall, uttered by an Italian native speaker. 


\subsubsection{German natives}

The analysis of the German native dataset reveals three positions of auch in the sentence base:

1. In SV structures, the particle is located in sentence-initial position, immediately preceding the NP (coded as 'auch NP VP');

2. $\quad$ or, immediately after the finite verb (i. e., 'NP Vfin auch (X) ');

3. in VS structures, the particle is always adjacent to the NP, either preceding (i. e., 'X Vfin auch NP') or following it (i. e., 'X Vfin NP auch').

The distribution of these four positional patterns is shown in Figure 5.

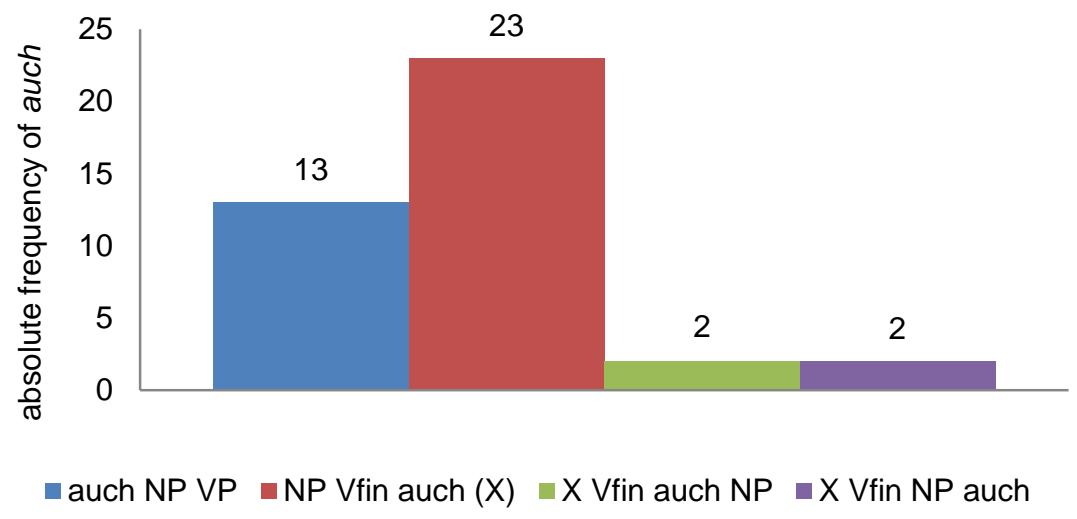

Figure 5: Positional embedding of the additive particle auch produced by 9 German native speakers, counts $(\mathrm{n}=40){ }^{5}$

In about one third of the cases, auch precedes its scope (the subject NP) in initial position (i. e., 'auch NP VP'). In these cases, auch is unaccented and the prominent tonal movement is on the NP. In most cases, the NP has a rising contour and is followed by a high-peak accent on the last constituent of the VP (see Figure 6; 7 times out of 11 occurrences). In the remaining cases (4 occurrences out of 11), the NP carries a falling tonal movement, whereas the following VP is deaccented.

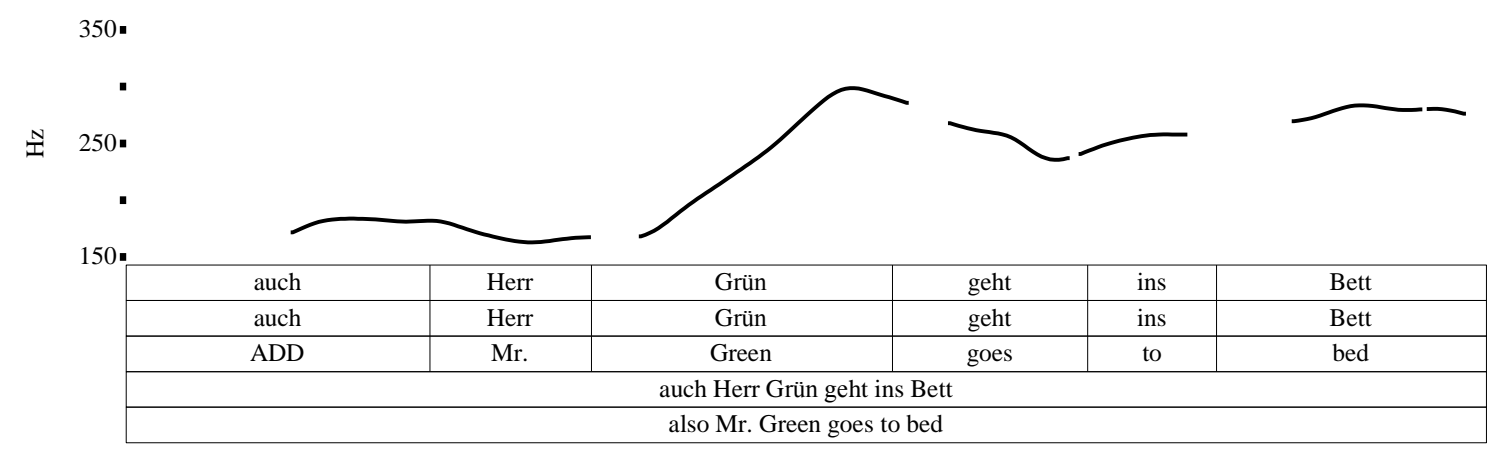

Figure 6: Pitch track example of 'auch NP VP' positional pattern with a rising accent on the topic Herr Grün ('Mr. Green') and high-plateau on the VP (i. e., geht ins bett 'goes to bed'), uttered by a German speaker.

$5 \mathrm{NP}$ stands for noun phrase, VP for verb phrase, Vfin for finite verb and X stands for any other constituent. 
Embedding additive particles in the sentence information structure: How L2 learners find their way through positional and prosodic patterns

Unaccented variants of the sentence-initial auch and the presence of a tonal movement on its "associated constituent" (here represented by the NP) have also been described in the German literature (see, for instance, Reis/Rosengren 1997).

In about two-thirds of the cases (i. e., 'NP Vfin auch (X)' in Figure 5), the particle is located after the finite verb, in the so-called wide scope position (König 1991). This positional pattern is either realised with a hat pattern contour (see, for instance, Braun 2006) - a rising movement on the NP followed by a high-plateau on the finite verb and a falling movement on auch (4 occurrences out of 13) - or, more predominantly, with a rising contour on the particle auch (and also on the preceding NP), followed by a high-plateau on the last constituent of the sentence ( 9 occurrences out of 13). This latter positional and prosodic preference is shown in Figure $7^{6}$.

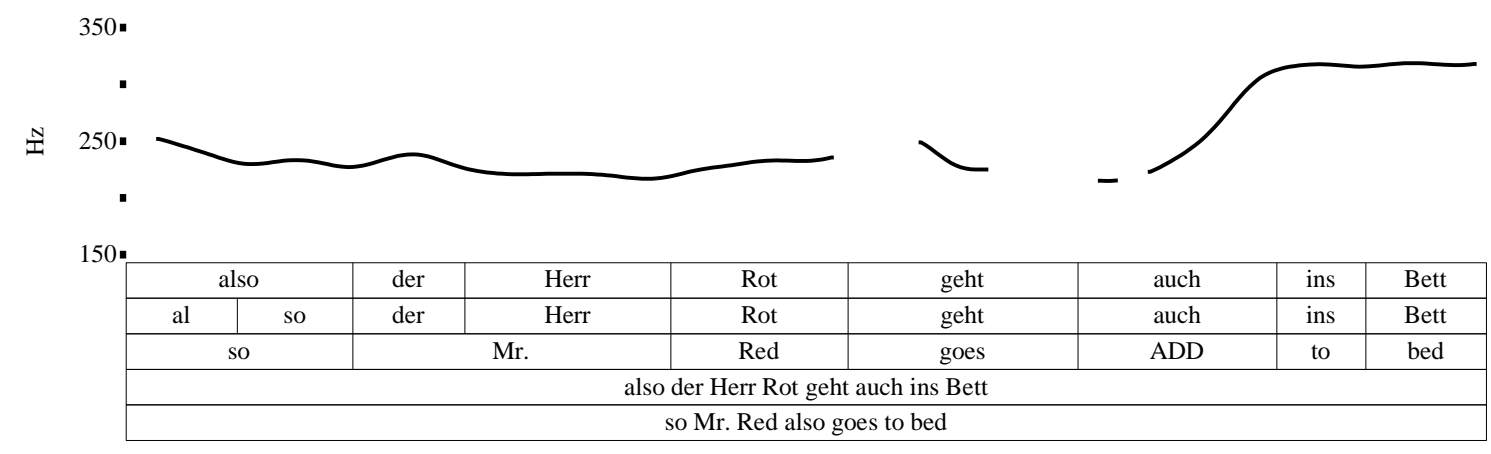

Figure 7: Pitch track example of the positional pattern 'NP Vfin auch $X$ ' with a slight rising movement on the NP followed by a rising contour on auch, uttered by a German speaker.

Accented variants of auch in post-finite position with rising tonal movements on the preceding NPs have also been reported in earlier work on the prosodic marking of topics in German (Krifka 1999; Sudhoff/Lenertová 2006; Braun 2013; Féry, forthcoming).

The patterns described so far concern sentences with an SV order, accounting for the majority of the cases. Only rarely (4 times out of 40, in the patterns 'X Vfin auch NP' and 'X Vfin NP auch', see Figure 5) the subject NP is found in post-finite verb position. In this position, the NP receives a prominent tonal (falling or rising) movement ( 2 occurrences out of 2 , see also Reis/Rosengren 1997 for similar observations), as shown in Figure 8.

6 An example hat pattern contour is shown in Appendix B. 


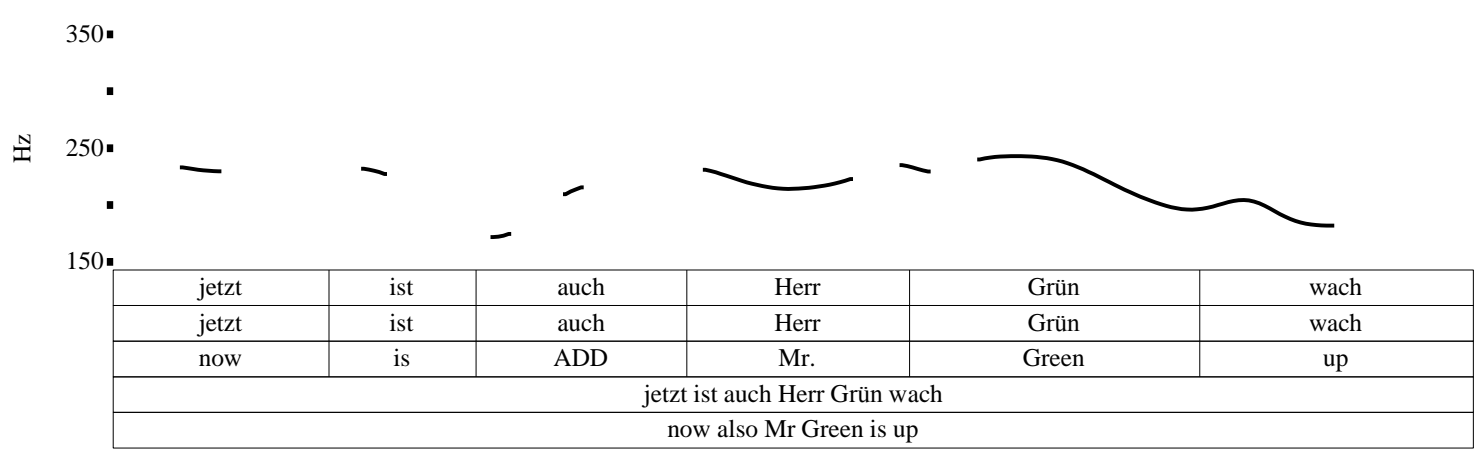

Figure 8: Pitch track example of the positional pattern 'X Vfin auch NP $X^{\prime}$ with a rising-falling contour on the NP, uttered by a German speaker.

\subsubsection{Interim discussion}

On the basis of the results presented in section 4.1.2, we can conclude that Italian and German speakers differ in some crucial aspects concerning the embedding of the additive particles in the base structure and the encoding of the information structure of the sentence. These differences are summarised in Figure 9 below.

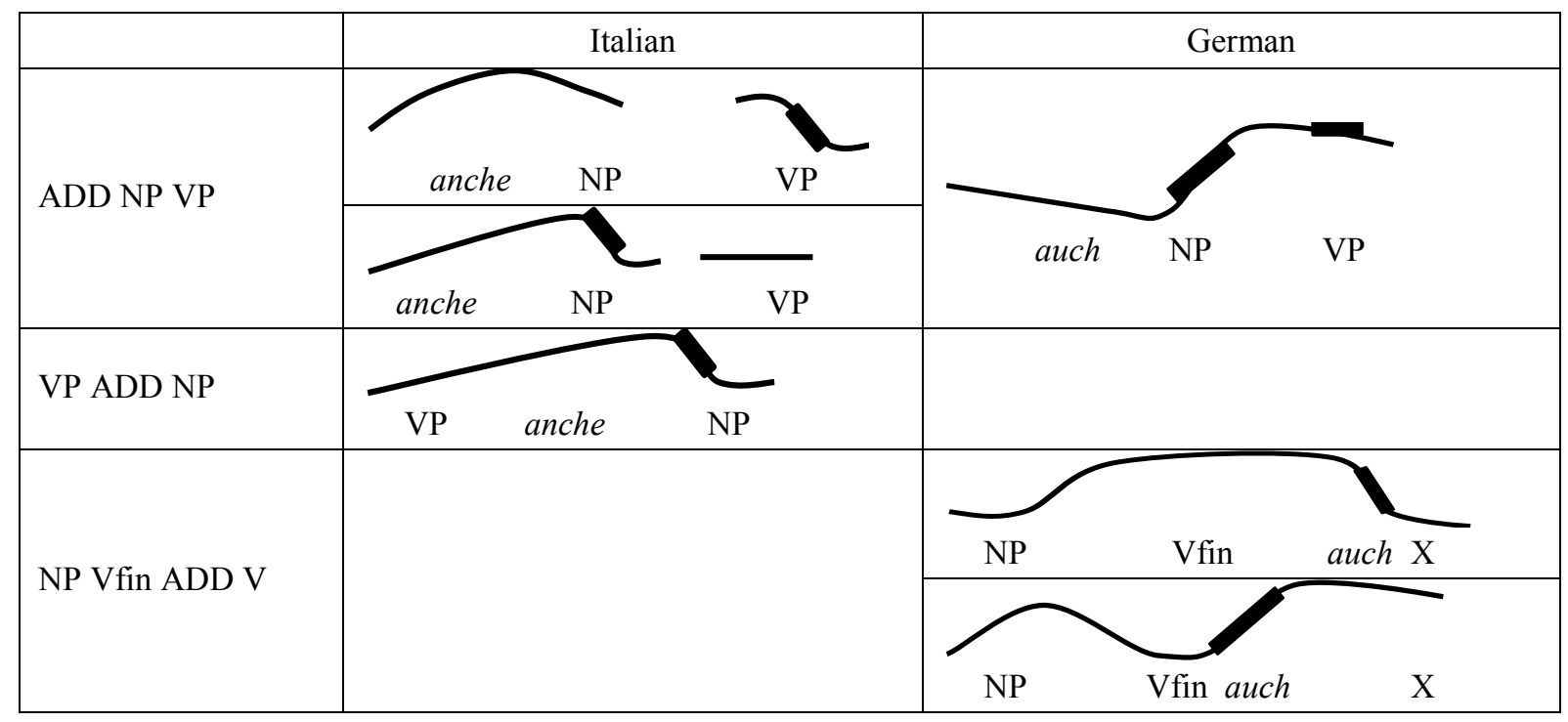

Figure 9: Comparison of the most frequent positional and prosodic patterns of the additive particles in Italian and German.

In organizing the sentence information structure, Italian speakers occasionally use word order or prosody to mark the subject as non-topical; this does not happen in German data. The sentence is often articulated in two prosodic movements in Italian (one on the NP, one on the VP), while German sentences are realised within a single prosodic movement.

In embedding the additive particle anche, Italian speakers strictly conform to an adjacency principle, thus marking the scope of anche mainly via positional strategies (i. e., the particle immediately precedes the NP in its scope). To encode the peculiar information structure of the sentence (i. e., the maintenance of the predicate and the changing of the subject referent) Italian speakers operate on the subject [anche $+\mathrm{NP}]$ constituent, either positionally (i. e., with 
Embedding additive particles in the sentence information structure: How L2 learners find their way through positional and prosodic patterns

the postposition of the subject) or prosodically (i. e., with focus-fronting of the subject). In all cases, anche is included in the same prosodic phrase of the NP and does not receive any specific positional or prosodic highlighting.

German speakers, on the other hand, prefer locating auch in post-finite position and mark its scope prosodically, either with a falling accent (i. e., via hat pattern contour) or, more typically, with a rising accent. In order to mark the information structure, they mainly use prosodic means: they highlight the subject [NP $+a u c h]$ constituent in initial position, or, more typically, the auch in the post-finite position.

These cross-linguistic differences may be taken to suggest a much stronger autonomy of auch and its much relevant role in marking the information structure of the sentence, when compared to anche. Anche is always positionally and prosodically included in the subject NP and cannot operate as a separate element occupying a prominent and isolated position, whereas auch most often occupies a prominent and isolated position and its highlighting is the sole element signalling a marked information structure. The stronger tendency of highlighting functional elements for pragmatic purposes in German, as compared to Romance languages like Italian and French, is also supported by results on verum focus, i. e. an accent on the auxiliary verb (Höhle 1992; Turco/Dimroth/Braun 2015 for Italian; Turco/Dimroth/Braun, 2013 for French).

These differences pose interesting questions from an acquisitional perspective. The learner's task is here twofold. To embed the sentences in the information flow, they have to acquire how to use marked sentence configurations that differ either positionally or prosodically from the base sentence structure of the target language. To embed an additive particle in the sentence, learners of Italian and of German have to acquire different scope-marking strategies (mainly positional in Italian, mainly prosodic in German).

\subsection{Learners}

\subsubsection{German learners of Italian}

The analysis of the German learners of Italian dataset reveals three positional patterns of anche:

1. in SV structures anche is either located in sentence-initial position, immediately preceding the NP (coded as 'anche NP VP'),

2. or immediately after the finite verb (i. e., 'NP Vfin anche (X) '),

3. in VS structures, anche is located in post-verbal position, immediately preceding the subject NP (i. e., 'VP anche NP'). 
Figure 10 shows the distribution of these three positional patterns split by learner ${ }^{7}$.

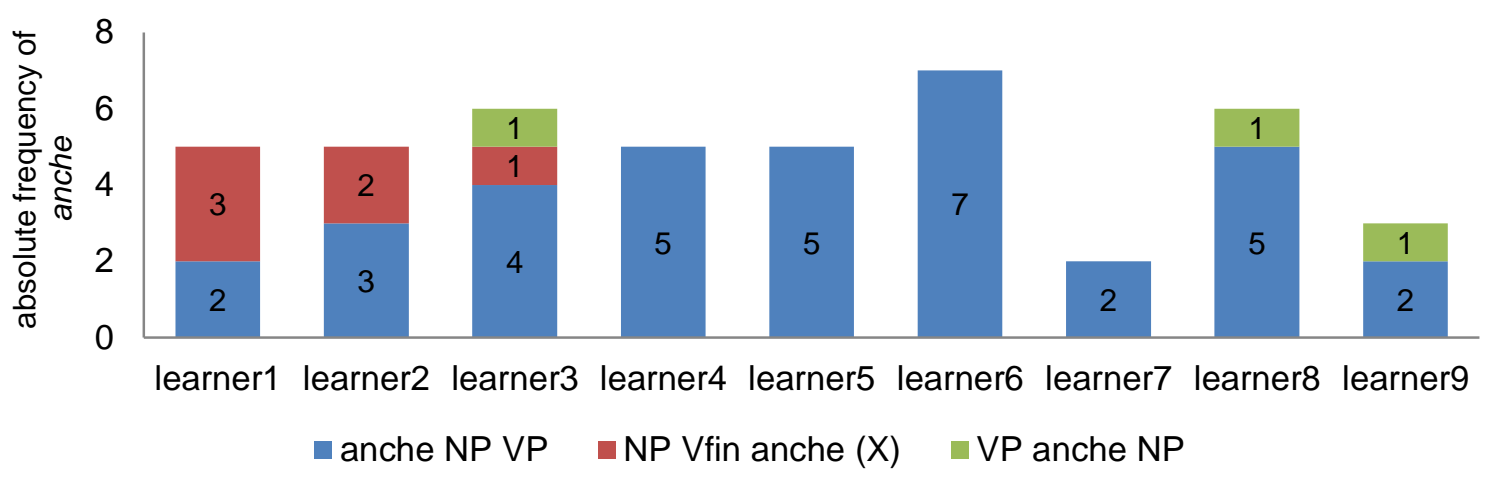

Figure 10: Positional embedding of the additive particle anche split by learner, counts $(n=44)$.

The 'anche NP VP' pattern, in the canonical SV order, is by far (35 occurrences out of 44) the most frequent; this is in line with the high frequency of initial [anche + NP] found in the target language (cfr. Figure 1). Note however that a similar positional pattern (i. e., initial $a u c h+\mathrm{NP})$ is also available in the source language, although it is not the preferred option. Indeed, in most cases (17 occurrences out of 24) the prosodic realization of these patterns seems to mirror the source language contour mapped onto a similar positional configuration of auch: a rising contour on the NP either followed by a rising accent or by a high peak accent on the VP (see Figure 11 below). Conversely, Italian native speakers tend to realise a falling accent on the last constituent of the NP constituent (compare with Figures 2 and 3).

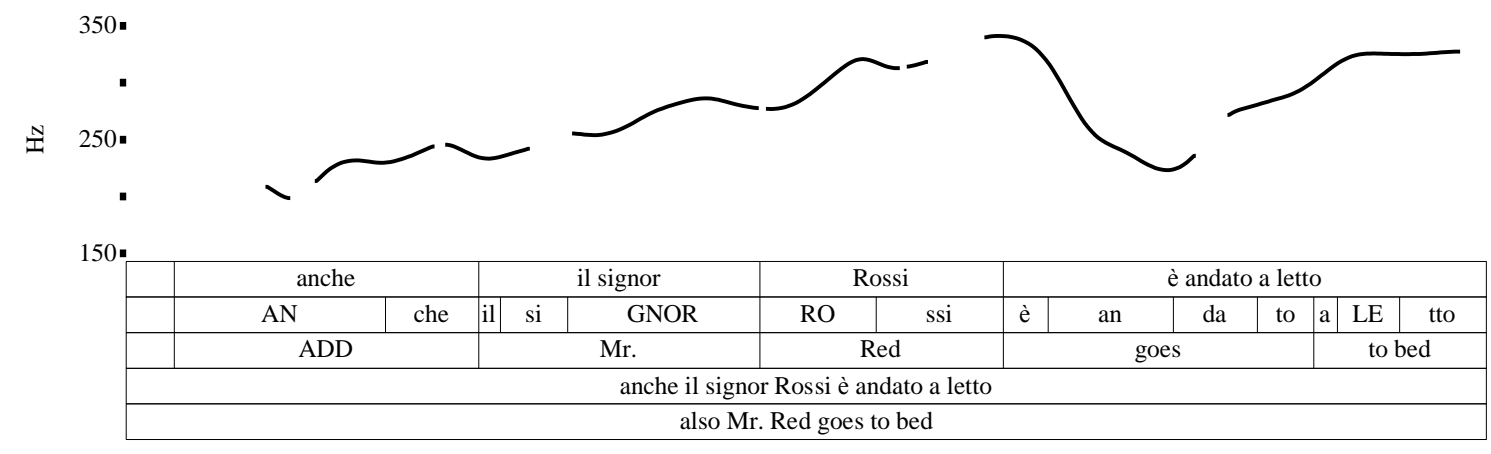

Figure 11: Pitch track example of 'anche NP VP' pattern with a rising contour on the NP followed by a rising contour on the VP, uttered by a German learner of Italian.

In the remaining cases (7 occurrences out of 24), the initial [anche + NP] is realised with a high-plateau on anche followed by a falling accent on the NP and a flat pitch on the VP, a prosodic pattern that is present - though only occasionally - in both the target and the native language.

Other positional patterns are only rarely found. In 6 cases out of 44, anche is postponed to the finite verb (i. e., 'NP Vfin anche (X)'). Such a position is not available in Italian but rather mirrors the most frequent pattern produced in the source language. This is further confirmed

7 In Figure 10, learners are ordered and grouped according to types of patterns they produce. A developmental sequence could therefore be suggested, but we cannot claim for it on the basis of our data. 
Cecilia Maria Andorno (Torino) and Giuseppina Turco (Stuttgart):

Embedding additive particles in the sentence information structure: How L2 learners find their way through positional and prosodic patterns

by the prosodic analysis (see Figure 12 below): the subject NP and anche are realised with a rising contour (in 4 cases out of 4 ) and followed by a peak-accent on the VP.

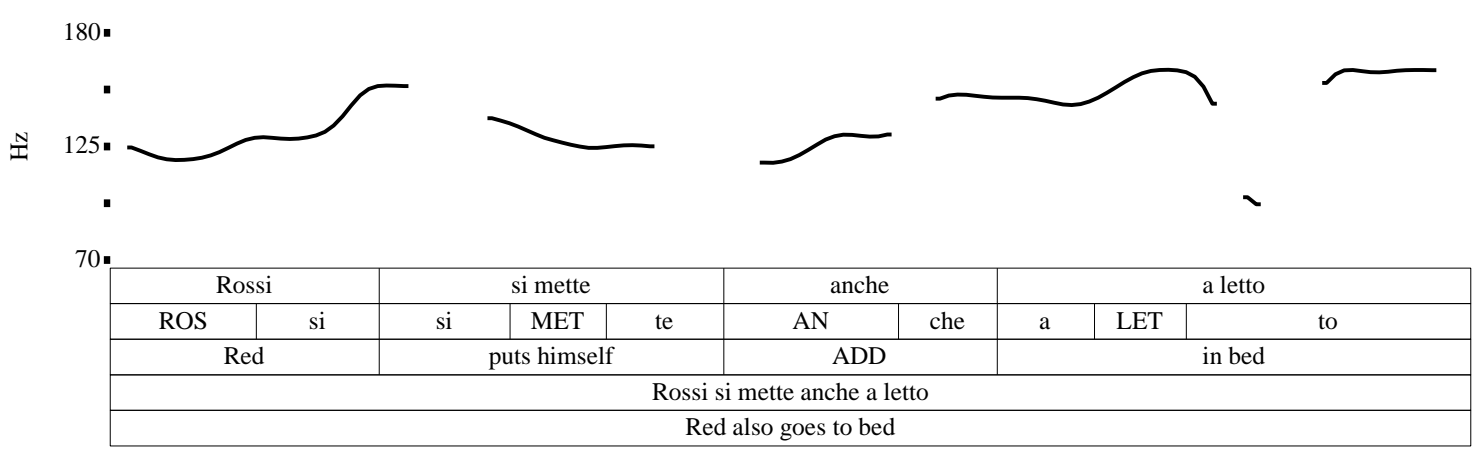

Figure 12: Pitch track example of 'NP Vfin anche $(\mathrm{X})$ ' pattern with a rising contour on anche followed by a rising contour on the VP, uttered by a German learner of Italian.

Finally, learners occasionally produce VS structures (3 occurrences out of 44) with anche located in post-verbal position and preceding the NP (i. e., 'VP anche NP'). This position is available in the target language and not found in the source language. It is probably to be seen as an acquisition of the target (language-specific) strategy. However, the only sentence we could analyse within these rare cases is characterized by a final rise on the NP (see Figure 13), not matching the pattern found in Italian (compare with Figure 4).

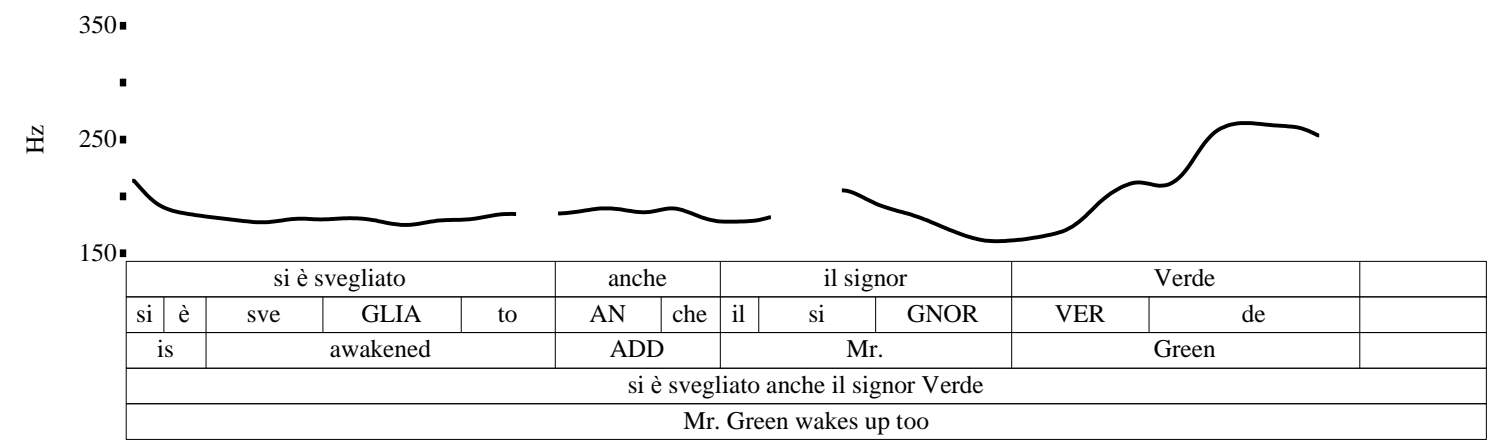

Figure 13: Pitch track example of 'VP anche NP' pattern with a rising contour on the NP, uttered by a German learner of Italian.

If we look at the individual results, from Figure 10 we can identify three groups of learners: two of them (i. e., learners 1 and 2) produce both the initial ('NP anche VP') and the postfinite position of anche ('NP Vfin anche $(\mathrm{X})$ '); the others have discarded the (non target) postfinite position and only place anche in the initial position, in line with the target language; the prosodic realization of these sentences, however, seems to be still influenced by the source language. Finally, only three learners (i. e., learners 3, 8, 9) occasionally recur to the postverbal NP-adjacent position in VS structures ('VP anche NP'). 


\subsubsection{Italian learners of German}

Italian learners of German always embed auch in SV structures according to three positional patterns:

1. In sentence-initial position, immediately preceding the NP (coded as 'auch NP VP'),

2. immediately following the NP ('NP auch $\mathrm{VP}$ '),

3. immediately after the finite verb ('NP Vfin auch $(\mathrm{X})$ ').

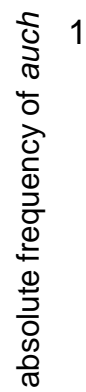

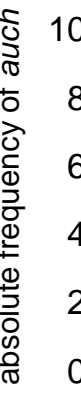

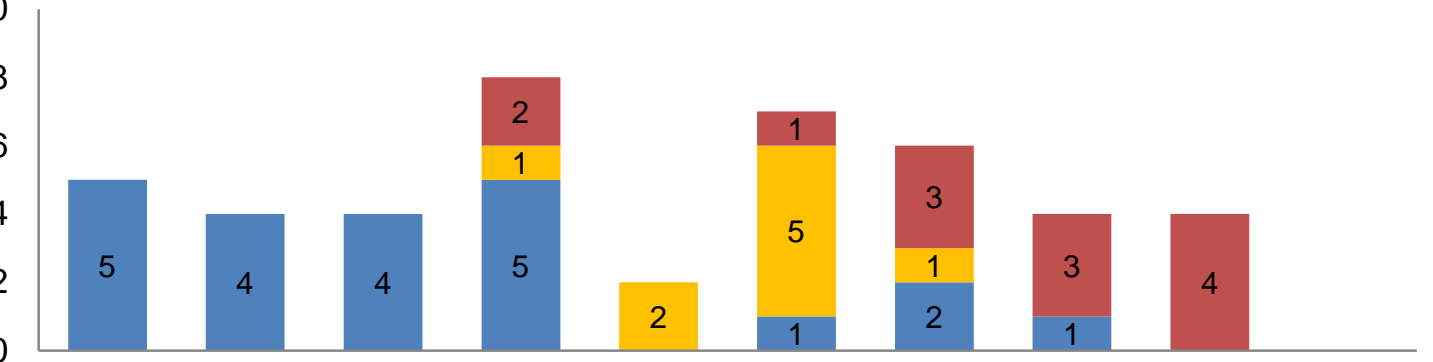

learner1 learner2 learner3 learner4 learner5 learner6 learner7 learner8 learner9

auch NP VP $\square$ NP auch VP $\square$ NP Vfin auch $(X)$

Figure 14: Positional embedding of the additive particle auch split by learner, counts $(n=44)$.

Initial auch (i. e., 'auch NP VP') accounts for half of the sentences (22 occurrences out of 44). This pattern is available in the target language, although it is not very frequently produced (remember that German native speakers prefer the post-finite position); it is however very frequent in the source language. The sentences are mostly realised with a prominent rising movement on the NP followed by a rising accent or a high-peak accent on the VP (10 occurrences out of 13, Figure 15), a prosodic pattern that is in line with the target language (compare with Figure 6). In the remaining cases (3 occurrences out of 13), learners produce a prosodic pattern mirroring their source language: a rise on the whole constituent $[a u c h+\mathrm{NP}]$ followed by a falling pitch on the VP.

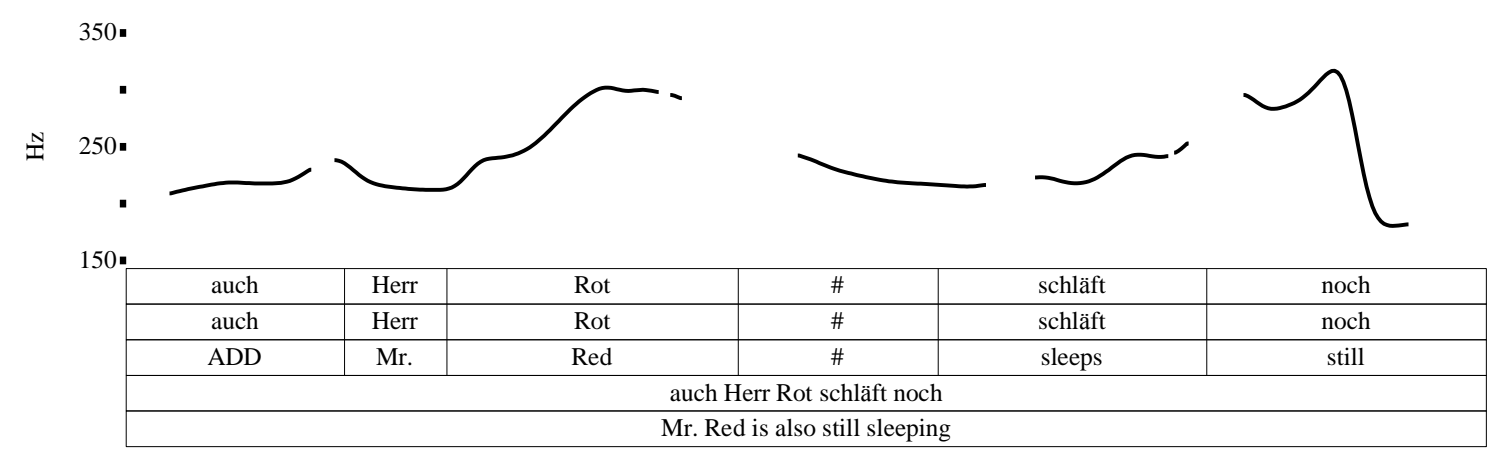

Figure 15: Pitch track example of 'auch NP VP' pattern with a rising contour on the NP followed by a rising contour on the VP, uttered by an Italian learner of German.

In the second positional pattern (i. e., 'NP auch VP') auch is still adjacent to the subject NP but postponed to it and preceding the VP ( 9 occurrences out of 44), a pattern that is rare in both the source and the target language (in our data, it only occurs in one case, see Figure 1). The prosodic contour of these sentences is characterised by a prominent rise on the NP 
Embedding additive particles in the sentence information structure: How L2 learners find their way through positional and prosodic patterns

followed by a final rising movement or a high-peak accent on the last constituent of the sentence (5 occurrences out of 5), as illustrated in Figure 16.

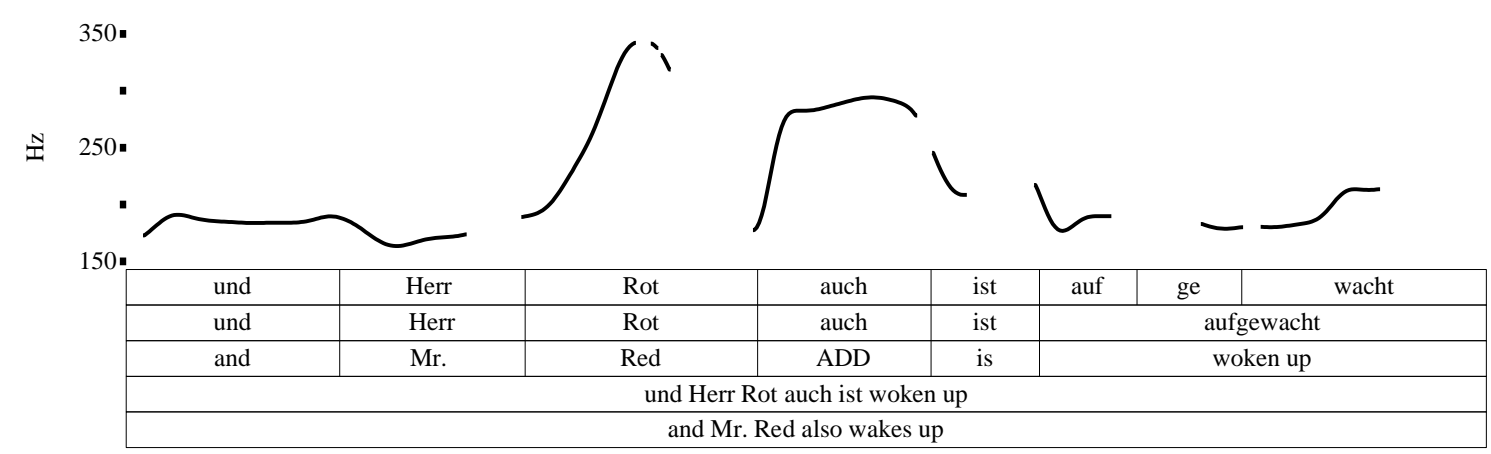

Figure 16: Pitch track example of 'NP auch VP' pattern with a rising contour on the NP and unaccented auch, uttered by an Italian learner of German.

In the third positional pattern, auch is found in post-finite position (13 occurrences of 44, 'NP Vfin auch $\left.(\mathrm{X})^{\prime}\right)$, which is very frequent in the target language and not available in the source language. This shows that learners have acquired a target language-specific position. However, this configuration is associated to different prosodic movements that all fail in marking auch in isolation (9 occurrences out of 9), as required by the target language (compare with Figure 7): in the same position, German speakers would highlight the additive operator with a rising accent. Hence, it appears that the use of this position does not come along with the acquisition of its related prosodic pattern. Figure 17, for instance, shows an example of rising accent on the NP followed by a deaccented auch.

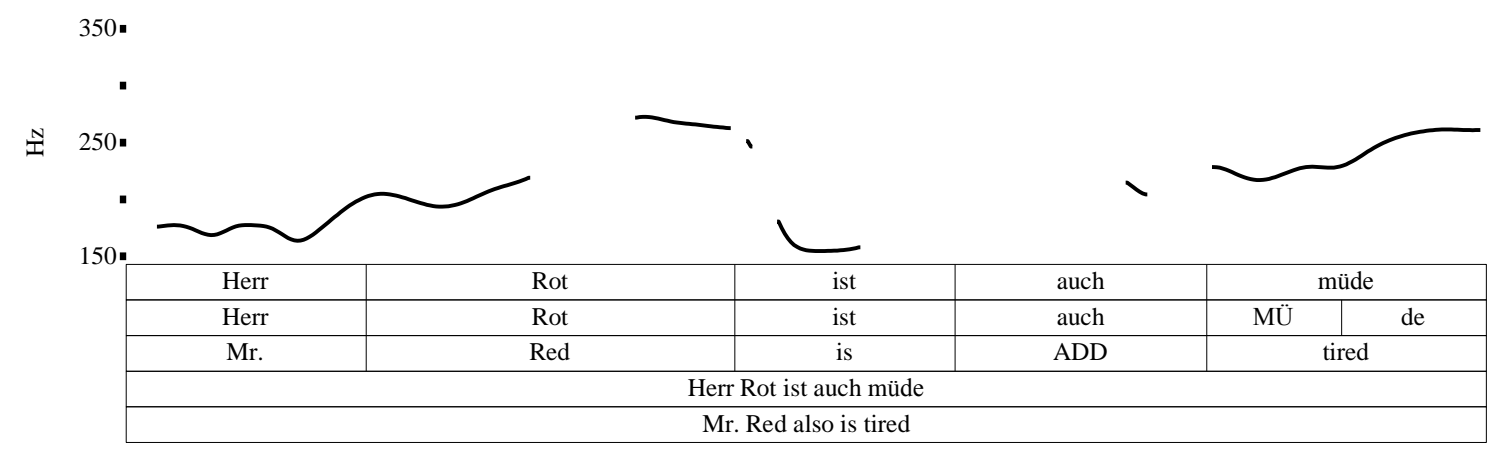

Figure 17: Pitch track example of 'NP Vfin auch $(\mathrm{X})$ ' pattern with unaccented auch preceded by a rising contour on the NP, uttered by an Italian speaker of German.

As Figure 14 shows, none of the patterns described above dominates the overall dataset; if we look at the individual data, we see that most of the learners stick to one specific pattern. Learners 1, 2, 3 and 4 mostly adopt the first pattern (anche preceding the NP), that is the most frequent one available in their source language; learners 8 and 9 mainly produce the third pattern (i. e., post-finite auch), which is the most target oriented; learners 5 and 6 mainly use the second pattern (i. e. 'NP auch VP'), rare in both native and target language. We can consider this pattern as a specific learner strategy towards the target language post-finite 
position, as we shall see in section 5. Only one learner (i. e., learner 7) uses a wider range of patterns.

\subsection{Interim discussion}

The analyses on learner productions reveal different acquisitional paths at a positional and prosodic level.

German learners of Italian seem to be mid-way towards the acquisition of the target language patterns. With regards to the positional embedding of anche, most learners abandoned the German post-finite position and mainly use the initial position, preceding the NP; on the other hand, the postposition of the whole [anche $+\mathrm{NP}$ ] constituent, the only completely new position to be learned, is found only occasionally. From a prosodic viewpoint, learner productions still seem to be influenced by the source language: in cases of 'anche NP VP' positional pattern, learners mostly produce a rising accent on the NP, which is line with previous studies on rising non-contrastive and contrastive topics in German (Braun 2006); such transfer effects were even more evident when anche was placed after the finite verb, a non target-like position in which the additive operator bears the prominent tonal movement.

The acquisitional behaviour of Italian learners of German seems to be a bit more complex than the one observed for German learners of Italian. In order to cope with the autonomy and the highlighting of auch, unavailable in their source language, learners adopt different strategies. Some only produce the initial NP-adjacent position; yet, most of them are also working on different non-initial, non-preposed positions. This partly results in the adoption of an independent auch in post-verbal position and partly in the postposition of auch after the NP (the pattern 'NP auch VP'). This latter can be seen as a way to maintain the strong adjacency principle of the source language, while moving anche from the initial position. Similar problems in giving autonomy to auch can be observed at a prosodic level: the particle is highlighted as part of the NP constituent (i. e., when it is postponed to the NP) but never highlighted in its autonomous post-finite position. Thus, learners may have acquired the proper post-finite position of auch but not yet its prosodic salience.

\section{Conclusion}

Generally speaking, our analyses provided further evidence that at an intermediate level of proficiency the embedding of additive particles in the sentence is still hard to acquire and does not conform the target language yet. We invoke two reasons for this learnability problem. The first is the lack of transparency in the input. Even within the same discourse context, target-language speakers make use of different patterns to express the same semantic content; therefore, learners lack of clear-cut evidence concerning what is and what is not possible in the target language. Moreover, the two languages involved - Italian and German share at least some positional patterns for the particles anche - auch (i. e., the initial position, preceding the NP): this perceived similarity (Kellerman 1977; Odlin 2003) possibly leads learners to reinforce an identity hypothesis between the grammar of scope in their native and in the target language, and, therefore, to cross-linguistic transfer. A second reason is linked to the fact that learners have to cope with marked structures, in which conflicts arise between basic pragmatic principles of sentence organization (e. g. "topic first", "focus last", "scope 
Cecilia Maria Andorno (Torino) and Giuseppina Turco (Stuttgart):

Embedding additive particles in the sentence information structure: How L2 learners find their way through positional and prosodic patterns

adjacency", Klein/Perdue 1997) and the syntactic rules acquired for the target languages (e. g., SV, finite verb): according to Klein/Perdue (1997), it is precisely these kinds of conflicting contexts that push learner varieties to diverge from a "basic" stage, based on "the interaction of a small number of organizational principles [...] largely independent of the specifics of source and target language organization" (Klein/Perdue 1997: 303), towards language-specific solutions. At this point, language-specific solutions can be taken from the source language, once again causing a stronger cross-linguistic influence. Similar crosslinguistic effects are known to arise at a discourse level (von Stutterheim 2003; Jarvis/Pavlenko 2007).

Coming to a more detailed discussion, our data confirm some previous results concerning the positional embedding of additive particles at the intermediate level: the post-finite position in L2 German, although frequent in the input, is not easy to acquire, and some learners still limit themselves to the initial pre-NP position (see also Benazzo 2005); on the other hand, our data show that German learners seem to be equally reluctant to discard the post-finite position in L2 Italian, even though this positional pattern is not available in the target language input.

Our data also suggest that the acquisition of the target-like positional patterns precedes the acquisition of the prosodic ones. This is true for the post-finite position in German, for which Italian learners fail to accent the particle, as already observed by previous studies (see $\S 2$ ) and is confirmed here by a more detailed prosodic analysis. But this is also true for the adjacent initial position in Italian: German learners adopt this position but they fail to deaccent the particle. However, prosody can also be seen as a driving force towards the target-like patterns, because of its possible enhancement of specific constituents in the input. In L2 German, a "prosodic bootstrapping"8 effect can be claimed to occur for the frequent use of an accented auch after the subject NP and right before the finite verb. This pattern - rarely found in both Italian and German native speakers - can accommodate an accented auch in internal position (which "copies" the frequent and salient post-finite additive particle of the target language input) with the strong adjacency principle of the source language. If this effect is true, then why does auch always fail to receive an accent whenever it is located on the proper post-finite position in L2 German? We believe that this is due to the systematic difference between German and Italian with regard to the treatment of functional words operating in the VP field. In German, the base sentence structure has a separate independent position for the finite verb and many verb modifiers (such as the negation nicht and phrasal adverbs noch, schon) are placed right after it; both the finite verb - irrespective of its being a full lexical verb, an auxiliary, a modal - and its modifiers can be independently focused for contrastive purposes. The most typical case of this property is represented by verum focus, in which the finite verb is expected to receive a focal accent. In the Italian sentence structure, on the other hand, the finite verb is immediately followed by the non-finite verb, and only a few adverbs can be placed in-between; moreover, the most frequent verb modifier, the negation, always preceding the whole verb complex, is itself a clitic and cannot be independently highlighted $^{9}$; even in cases of a Verum Focus interpretation, in the majority of the cases the

8 The term is taken from L1 acquisition studies, where it is used for the hypothesis that young learners use prosodic cues to determine the sentence syntactic structure (cf. Morgan/Dermuth 1996 for a discussion). 9 Unless in very specific cases (as is the case of metalinguistic negation).

ISSN 1615-3014 
focus accent is not located on the finite verb, but on the last constituent of the complex verb (Turco et al., 2013, 2015). To sum up, functional words in the VP can be both positionally and prosodically highlighted as an independent element in German but not in Italian: this difference reflects the existence of language-specific ways in constructing the information structure of the sentence (cf. Dimroth et al. 2010).

Previous studies on German adults and children (cf. Dimroth et al. 2010 and Benazzo/Dimroth, this issue) show that both groups of speakers are highly sensitive to the illustrated verum-focus properties and exploit the post-finite verb position for contrastive purposes, with negation, polarity particle doch, phrasal adverb noch and wide scope auch. Studies on second language acquisition, on the other hand, show that Italian learners of German need time to learn the post-finite position for negation and phrasal particles (Benazzo 2005; Giuliano 2004); similarly, in our study it was shown that the acquisition of the postfinite auch does not come along with the acquisition of the target-like prosodic pattern. Our Italian learners are still not able to highlight the additive particle in an isolated post-finite position. We think that all these acquisitional phenomena have to be considered as part of a cross-linguistic influence between the "Germanic" and the "Romance" way in sentence structuring.

\section{References}

Andorno, Cecilia (2000): Focalizzatori e messa a fuoco. Il punto di vista delle varietà di apprendimento. Milano: Franco Angeli.

Andorno, Cecilia (2005): "Additive and Restrictive Particles in Italian as a Second Language". In: Hendricks, Henriette (ed.): The structure of learner varieties. Berlin, Mouton de Gruyter: 405-460.

Andorno, Cecilia/Interlandi, Grazia (2010): "Topics? Positional and prosodic features of subjects in additive sentences in Italian L1". In Chini, Marina (ed): Topic, information structure and language acquisition. Milano, Franco Angeli: 73-94.

Becker, Angelika/Rainer Dietrich (1996): "The acquisition of scope in German". Zeitschrift für Literaturwissenschaft und Linguistik 104: 115-141.

Benazzo, Sandra (2005): "Le développement des lectes d'apprenants et l'acquisition de la portée à distance en L2". Acquisition et Interaction en Langue Étrangère 23: 65-93.

Benazzo, Sandra/Andorno, Cecilia (2010): "Discourse Cohesion and Topic Discontinuity in native and learner production: Changing topic entities on maintained predicates". In: Roberts, Leah/Howard, Martin/Singleton, David (eds.): EuroSLA Yearbook 10. Amsterdam, Benjamins: 92-118.

Bocci, Giuliano/Avesani, Cinzia (2006): "Focus contrastivo nella periferia sinistra della frase: un solo accento, ma non solo un accento". In Savy, Renata/Crocco, Claudia (eds): Analisi Prosodica - Teorie, modelli e sistemi di annotazione (Vol. II - Proceedings of the 2nd National Conference "Associazione Italiana di Scienze della Voce" (AISV). Torriana, EDK Editore: 1-30.

Boersma, Paul/Weenink, David (2012): Praat. Doing phonetics by computer (Version 5.3.34). Amsterdam. Retrieved from http://www.praat.org, accessed July 28, 2015.

Braun, Bettina (2006): "Phonetics and phonology of thematic contrast in German". Language and Speech 49/4: 451-493. 
Embedding additive particles in the sentence information structure: How L2 learners find their way through positional and prosodic patterns

Braun, Bettina (2013): "Where to Associate Stressed Additive Particles?: Evidence from Speech Prosody". Proceedings of the 13th annual conference of the International Speech Communication Association 2012 (INTERSPEECH 2012): Portland, Oregon, USA, 9.-13. September 2012 / International Speech Communication Association. Red Hook-New York, Curran: 678-681.

CEFR (2011): Common European Framework of Reference for Languages. Learning, Teaching, Assessment. Retrieved from http://www.coe.int/t/dg4/linguistic/Cadre1_en.asp, accessed July 28, 2015.

Cresti Emanuela/Firenzuoli Valentina (2002): "L'articolazione informativa topic-comment e comment-appendice: correlati intonativi". In: Regnicoli, Agostino (ed): La fonetica acustica come strumento di analisi della variazione linguistica in Italia. Atti delle XII Giornate di Studio del G.F.S. Roma, Il Calamo: 153-160.

Crocco, Claudia/Savy, Renata (2007): "Topic in dialogue: prosodic and syntactic features". Paper presented at the Interspeech (ISCA) 2007, Antwerp: 114-117. Available at http://www.isca-speech.org/archive/interspeech_2007/i07_0114.html, accessed July 28, 2015.

Dimroth, Christine (1998): "Indiquer la portée en allemand L2. Une étude longitudinale de l'acquisition des particules de portée". Acquisition et Interaction en Langue Étrangère 11: $11-34$.

Dimroth, Christine et al. (2010): "Given claims about new topics. How Romance and Germanic speakers link changed and maintained information in narrative discourse". Journal of Pragmatics 42/12: 3328-3344.

Féry, Caroline (2012): "Prosody and information structure of the German particles selbst, wieder and auch". In: Borowsky, Toni et al. (eds.): Prosody Matters. Essays in Honor of Elisabeth O. Selkirk. London, Equinox Press: 420-455.

Firenzuoli, Valentina/Signorini, Sabrina (2003): "L'unità informativa di Topic: correlati intonativi". In: Marotta, Giovanna/Nocchi, Nadia (eds): La coarticolazione. Pisa, Edizioni ETS: $177-184$.

Giuliano, Patrizia (2004): La négation dans l'acquisition d'une langue étrangère. Un débat conclu? Bern: Peter Lang.

Höhle, Tilman. (1992): "Über Verum-Fokus im Deutschen". In: Jacobs, Joachim (ed): Informationsstruktur und Grammatik. Opladen, Westdeutscher Verlag: 112-141.

Jarvis, Scott/Pavlenko, Aneta (2008): Crosslinguistic Influence in Language and Cognition. New York: Routledge.

Kellerman, Eric (1977): "Toward a characterization of the strategy of transfer in second language learning". Interlanguage Studies Bulletin 2: 58-145.

Klein, Wolfgang (1986): Second language acquisition. Cambridge: Cambridge University Press.

Klein, Wolfgang/Perdue, Clive (1997): "The Basic Variety (or: Couldn't natural languages be much simpler?)". Second Language Research 13/4: 301-347.

König, Ekkehard (1991): The meaning of focus particles: A comparative perspective. London and New York: Routledge.

Krifka, Manfred (1999): "Additive particles under stress". Proceedings of SALT 8. Cornell: CLC Publications: 111-128. 
Lambrecht, Knud (1994): Information Structure and Sentence Form. Topic focus and the mental representations of dicourse referents. Cambridge: Cambridge University Press.

Leray, Estelle (2009): "Additive focus particles in bilingual language acquisition". In: Düfter, Andreas/Jacob, Daniel (eds): Focus and background in Romance languages. Amsterdam, Benjamins: 205-238.

Levelt, Willem J. M. (1989): Speaking: From Intention to Articulation. Cambridge, MA, MIT Press.

Mennen, Ineke (2004): "Bi-directional interference in the intonation of Dutch speakers of Greek". Journal of Phonetics 32/4: 543-563.

Mereu, Lunella/Frascarelli, Mara (2006): "L'interfaccia sintassi-fonologia: interpretazione e implicazioni teoriche". In: Savy Renata/Crocco Claudia (eds) : Analisi prosodica: teorie, modelli e sistemi di annotazione, Atti del $2^{\circ}$ Convegno Nazionale AISV. Padova, ISTC/EDK: 256-284.

Morgan, James L./Demuth, Katherine (eds.) (1996): Signal to syntax: Bootstrapping from Speech to Grammar in Early Acquisition, Mahwah: Erlbaum.

Odlin, Terence (2003): "Cross-linguistic influence". In: Doughty, Catherine/Long, Michael (eds): Handbook on Second Language Acquisition. Oxford, Blackwell: 436-486.

Rasier, Laurent/Hiligsmann, Philippe (2007): "Prosodic transfer. Theoretical and methodological issues". Nouveaux cahiers de linguistique française 28: 41-66.

Reis, Marga/Rosengren, Inger (1997): "A modular approach to the grammar of additive particles: The case of German auch". Journal of Semantics 14/3: 237-309.

Stutterheim, Christiane von (2003): Linguistic structure and information organization: The case of very advanced learners (Vol. 3). Amsterdam: Benjamins.

Stutterheim, Christiane von/Klein, Wolfgang (2002): "Quaestio and L-Perspectivation". In: Graumann, Carl Friedrich/Kallmeyer Werner (eds): Perspective and perspectivation in discourse. Amsterdam, Benjamins: 59-88.

Sudhoff, Stefan/Lenertová, Denisa (2006): "Prosodic properties of constituents associated with stressed auch in German". In: Hoffmann, Rüdiger/Mixdorff, Hansjörg (eds): Proceedings of Speech Prosody 2006, Dresden, Bd. 1. Dresden, TUDpress: 390-393.

Turco, Giuseppina/Dimroth, Christine/Braun, Bettina (2013): "Intonational means to mark Verum focus in German and French". Language and Speech 56: 461-491.

Turco, Giuseppina/Dimroth, Christine/Braun, Bettina (2015): Prosodic and lexical marking of contrast in L2 Italian. Second Language Research. Available online: April 09 2015, DOI: $10.1177 / 0267658315579537$.

Turco, Giuseppina/Gubian, Michele (2012, 22-25 May): "L1 Prosodic transfer and priming effects: A quantitative study on semi-spontaneous dialogues". Proceedings of the 6th International Conference on Speech Prosody, Shangai: 386-389. 
Cecilia Maria Andorno (Torino) and Giuseppina Turco (Stuttgart):

Embedding additive particles in the sentence information structure: How L2 learners find their way through positional and prosodic patterns

Appendix A

\begin{tabular}{|l|c|c|}
\hline Prosodic analysis & Italian natives & German learners of Italian \\
\hline Anche NP VP & 20 & 24 \\
\hline NP anche VP & 6 & 4 \\
\hline VP anche NP & 5 & 1 \\
\hline NP Vfin anche & 0 & 0 \\
\hline total & 31 (out of 96) & 29 (out of 44) \\
\hline
\end{tabular}

Table 3: Number of sentences analysed prosodically for each positional configuration of anche in the Italian native dataset and the German learners of Italian dataset. Sentences not included in the analysis were discarded due to the presence of hesitations and disfluencies.

\begin{tabular}{|l|c|c|}
\hline Prosodic analysis & German natives & Italian learners of German \\
\hline Auch NP VP & 11 & 13 \\
\hline NP Vfin auch & 13 & 9 \\
\hline Vfin auch NP & 0 & 0 \\
\hline X Vfin NP auch & 2 & 0 \\
\hline NP auch VP & 0 & 5 \\
\hline Total & 26 (out of 40) & 27 (out of 44) \\
\hline
\end{tabular}

Table 4: Number of sentences analysed prosodically for each positional configuration of auch in the German native dataset and the Italian learners of German dataset. Sentences not included in the analysis were discarded due to the presence of hesitations and disfluencies.

\section{Appendix B}

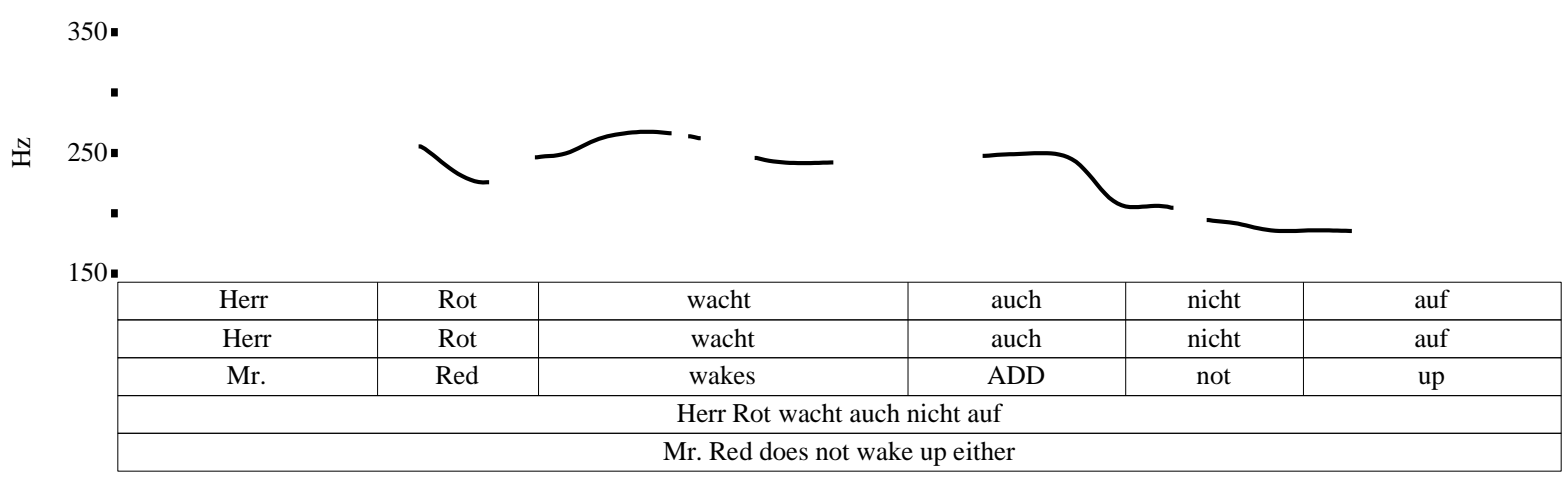

Figure 18: Pitch track example of the positional pattern NP Vfin auch with a hat pattern contour, uttered by a German speaker. 